\title{
The Status Quo of Doctors' Occupational Burnout and Its Correlation with the Cognition of Doctor-patient Relationship Tensity
}

\section{Type}

Research paper

\section{Keywords}

doctor, occupational burnout, doctor-patient relationship

\begin{abstract}
Introduction

To understand the status quo of doctors' occupational burnout, analyze the correlation between the occupational burnout and cognition of tensity of doctor-patient relationship (DPR).

Material and methods

Take 265 doctors in a general hospital in China as respondents, conduct a survey of the degree of occupational burnout with Maslach Burnout Inventory, score the cognitive quantification of DPR tensity with Difficult Doctor-Patient Relationship Questionnaire-8, and analyze the correlation between them. The cognitive quantitative scores of DPR tensity were also given to 782 inpatients and compared with the doctors' cognitive scores.
\end{abstract}

\section{Results}

The degrees of occupational burnout in doctors, including three dimensions of emotional exhaustion, depersonalization and sense of personal achievement, were high. The proportions of moderate or more burnout were $49.8 \%, 53.2 \%$ and $48.7 \%$, respectively. There was a statistical difference in occupational burnout among doctors of different ages and professional titles $(P<0.05)$. Doctors' cognition of DPR tensity was significantly worse than patients' cognition $(P<0.01)$. The degrees of emotional exhaustion and dehumanization were positively correlated with the poor cognition of DPR tensity in doctors $(P<0.001)$. The degree of sense of personal achievement was negatively correlated with the poor cognition in doctors $(P<0.001)$.

\section{Conclusions}

Doctors' age and professional title are important factors that affect the high degree of occupational burnout. Doctors do not have positive cognition of DPR tensity, which is different from that of patiens. The degree of occupational burnout is closely related to the poor cognition of DPR tensity in doctors. 


\title{
The Status Quo of Doctors' Occupational Burnout and Its Correlation with the Cognition of Doctor-patient Relationship Tensity
}

Running head: Occupational Burnout \& Doctor-patient Relationship

\begin{abstract}
Introduction: To understand the status quo of doctors' occupational burnout, analyze the correlation between the occupational burnout and cognition of tensity of doctor-patient relationship (DPR).
\end{abstract}

Methods: Take 265 doctors in a general hospital in China as respondents, conduct a survey of the degree of occupational burnout with Maslach Burnout Inventory, score the cognitive quantification of DPR tensity with Difficult Doctor-Patient Relationship Questionnaire-8, and analyze the correlation between them. The cognitive quantitative scores of DPR tensity were also given to 782 inpatients and compared with the doctors' cognitive scores.

Results: The degrees of occupational burnout in doctors, including three dimensions of emotional exhaustion, depersonalization and sense of personal achievement, were high. The proportions of moderate or more burnout were $49.8 \%, 53.2 \%$ and $48.7 \%$, respectively. 
There was a statistical difference in occupational burnout among doctors of different ages and professional titles $(P<0.05)$. Doctors' cognition of DPR tensity was significantly worse than patients' cognition $(P<0.01)$. The degrees of emotional exhaustion and dehumanization were positively correlated with the poor cognition of DPR tensity in doctors $(P<0.001)$. The degree of sense of personal achievement was negatively correlated with the poor cognition in doctors $(P<0.001)$.

Conclusions: Doctors' age and professional title are important factors that affect the high degree of occupational burnout. Doctors do not have positive cognition of DPR tensity, which is different from that of patients. The degree of occupational burnout is closely related to the poor cognition of DPR tensity in doctors.

Keywords: occupational burnout, doctor-patient relationship, doctor.

\section{Introduction}

Today, as the trust degree between doctors and patients continues to decline, the tense doctor-patient relationship (DPR) becomes an industry-wide problem. In 2018, the China Medical Association survey showed that there were 90,000 medical disputes in China in 2016 , in which there were above $50 \%$ of medical staff subjected to verbal violence and $15 \%$ of the medical staff suffered physically hurt [1]. As an industry in frequent contact with sick patients, doctors require a strong sense of responsibility and cognitive and emotional 
abilities [2]. Under the influence of tense DPR, doctors are prone to develop a sense of identity and alertness, increase psychological pressure and subjectively create a poor cognition of DPR tensity. Moreover, doctors have to face heavy workloads, such as night shifts, surgery, writing medical records and so on. Various pressures cause doctors to be prone to occupational burnout [2,3-6].

Conversely, doctors with occupational burnout are prone to poor communication and more frictions with patients due to the decline of their enthusiasm for work, emotional control and communication expectations, which may further aggravate doctors' poor cognition of DPR tensity [7]. Such a vicious circle will inevitably bring about enormous social problems and intensify the contradiction between doctors and patients.

So we consider that there may be a causal relationship between the degree of occupational burnout and cognition of DPR tensity in doctors. However, it's unpersuasive because there is no study on correlation between both at present. Therefore, this study quantifies the degree of doctors' occupational burnout in a general hospital, evaluated respectively the cognitions of DPR tensity in doctors and patients, and analyze theirs correlations and propose some targeted intervention measures.

\section{Material and Methods}

\section{Study population}

300 clinical doctors were selected randomly as study objects from a general hospital in 
China. We issued 300 questionnaires and got back 281 copies of them, among which there were 265 valid copies. The effective rate was $94.3 \%$. The baseline information of doctors included age, sex, educational background and professional title. The inpatients who were in charge by the above-mentioned doctors ( 3 per doctors) were randomly selected as patient survey objects. A total of 795 questionnaires were handed in person to patients by our researchers, and recovered by us on site after patients completed the questionnaires. 782 were recovered and valid. The effective rate was $100 \%$. Studies were performed with the understanding and consent of each subject including doctors and patients, with the approval of the Ethics Committee of Zhengzhou University. Each subject signed informed consent.

\section{Quantitative evaluation for the degree of occupational burnout}

The questionnaire of Maslach Burnout Inventory-General Survey (MBI-GS) [8] was applied to evaluate the degree of occupational burnout in doctors including three aspects of emotional exhaustion, depersonalization and sense of personal achievement. The burnout scoring criteria of three aspects are as follows: the scores of mild burnout are less than 9 , less than 3 and more than 18 points, scores of moderate burnout are $9 \sim 13,3 \sim 9$ and 18 30, and scores of high burnout are more than 13, more than 9 and less than 18 points, respectively. The Cronbach's $\alpha$ coefficient of three aspects were respectively $0.87,0.81$ and 0.82 , which were of high reliability. 


\section{Quantitative evaluation for the tensity of DPR}

The Difficult Doctor-Patient Relationship Questionnaire-10 (DDPRQ-10) [9,10] is widely used to quantitatively evaluate the cognitive situation of DPR tensity in doctors. The Patient-Doctor Relationship Questionnaire-15 (PDRQ-15) was developed by Van der Feliz-Cornelis et al in 2004 for evaluating the patients' cognition of DPR tensity [11]. It has been developed into a multinational version for evaluation and application [11-14]. Yang $\mathrm{H}$ et al revised them to form a Chinese-specific DDPRQ-8 and PDRQ-13, which had good reliability and validity $[15,16]$. The contents and scoring methods of DDPRQ-8 and PDRQ-13 were respectively shown as Table I and Table II. The higher the score was, the harder the difficulty doctors or patients faced was in DPR and the more serious the DPR tensity was. The $50 \%$ of theoretical maximum scores of DDPRQ-8 and PDRQ-13 are 24 and 32.5 points respectively. The scores are higher or equal to 24 or 32.5 points, suggesting that doctors or patients have poor cognition of DPR tensity, and lower than the scores, suggesting a good cognition.

\section{Statistical analysis}

All data were analyzed using SPSS 22.0 statistical software. According to age, sex, educational background and professional title, the differences between the occupational 
burnout scores of each group were compared by the one-way ANOVA (homogeneity of variance assumptions were satisfied) or Kruskal-Wallis test (homogeneity of variance assumptions were not satisfied). The difference of the cognitions of DPR tensity between doctors and patients was compared by Chi-square test. The correlation between the degree of occupational burnout and cognition of DPR tensity in doctors were analyzed by both the Spearmen correlation analysis and Chi-square test. The differences were considered to be statistically significant when the adjusted $P$ values were $<0.05$.

\section{Results}

\section{The baseline information of doctors}

There were 256 doctors (172 males and 93 females) as respondents in 22 departments from internal, surgery, gynaecology and obstetrics, paediatrics, ophthalmology, otorhinolaryngology, emergency et al. The average age was $39.6 \pm 8.76$ (40.7 \pm 8.21 in males, $37.5 \pm 9.38$ in females) years. The specific baseline information of age, sex, educational background and professional title were shown in Table III.

\section{The degree proportions of occupational burnout in doctors}

The degree proportions of occupational burnout in doctors on three dimensions 
(emotional exhaustion, depersonalization and sense of personal achievement) were shown in Table IV. The ratios of doctors with moderate and severe burnout in three dimensions were $49.8 \%, 53.2 \%$ and $48.7 \%$ respectively, which all reached about half.

\section{The degrees of occupational burnout under the baseline information of doctors}

According to ages, the score of sense of personal achievement was lowest in doctors under 30 years old, and highest in doctors aged 41 to 50 . There were statistically significant differences $(P=0.003)$. There were no significant differences in the scores of emotional exhaustion and depersonalization respectively $(P>0.05)$. According to professional titles, the score of emotional exhaustion in attending physicians was higher than that in chief physicians $(P=0.024)$. The scores of sense of personal achievement in resident and attending physicians were lower than that in chief physicians $(P=0.009)$. There were no significant differences in the scores of depersonalization $(P>0.05)$. According to sex and educational background, there were all no statistically significant differences in the three dimensions of occupational burnout $(P>0.05)$ (Table III).

\section{Comparisons of both doctors and patients' cognitions of DPR tensity}


Doctors generally held a negative attitude towards DPR. The average scores of doctors' cognitions of DPR tensity were closed to 24 points in almost all departments, and more than 24 points in $40.91 \%$ of departments. The top three departments with poor cognitions of DPR tensity were respiratory, emergency and gastrointestinal surgery departments. The patients' cognition of DPR tensity was more optimistic than that of doctors. The cognitive scores in patients in all departments were obviously lower than 32.5 points. They thought that DPR was good, and the overall trend of cognitions was stable (Table V). Chi-square analysis showed that there are statistically significant differences in the cognitive scores of DPR tensity between doctors and patients $\left(\chi^{2}=290.178, P<0.0001\right)$ (Table VI).

The correlation between the degrees of occupational burnout and cognition of DPR tensity in doctors

Spearmen correlation analysis results suggested that the emotional exhaustion and depersonalization were positively correlated with the poor cognition $(r=0.574, P<0.0001$; $r=0.548, P<0.0001$ ) (Figure 1A and 1B), while the sense of personal achievement was negatively correlated with that $(r=-0.255, P<0.0001)$ (Figure 1C).

Doctors with low occupational burnout had good cognition of DPR tensity, with $77.4 \%$, $79.2 \%$ and $65.4 \%$ of doctors having good cognition of depersonalization, emotional exhaustion and personal accomplishment respectively. Doctors with high occupational 
burnout generally have poor cognition of DPR tensity, with $80.7 \%, 70.7 \%$ and $58.8 \%$ of doctors having poor perception of three dimensions respectively. Chi-square test results indicated that doctors' cognition of DPR tensity had statistical significance under different degrees of occupational burnout $(P<0.01)$ (Table VII).

\section{Discussion}

Occupational burnout was first proposed by American psychiatrist Freudenberger in 1974, and refers to a state of extreme exhaustion caused by excessive demand for energy and all the resources which an individual possesses [17]. As the pressure of social competition increases, the phenomenon of occupational burnout becomes more and more common and can affect a wide range of professions, but people who are engaged in work that helps others are particularly vulnerable to this effect [18]. It could not be ignored that a high degree of occupational burnout exists in medical staff [19-22].

Burnout is a syndrome of emotional exhaustion, depersonalization and reduced personal achievement that can occur among individuals who do "people work" of some kind" [23]. Our study found that in general hospital, about half of doctors have moderate or severe burnout in each of the three dimensions including emotional exhaustion, depersonalization and sense of personal achievement. More than a third of doctors were with severe emotional exhaustion. 
The degree of emotional exhaustion was most severe in attending physicians, which was not noticed in previous studies [24]. The reasons may be as follows: attending physicians are responsible for the main clinical work in the department, as well as the heavy research and teaching tasks; their labor intensity is great while the work position is relatively low; they also face various pressures from superior physicians, patients, promotion and career development.

However, the occupational burnout of resident physicians was mainly reflected in the low sense of personal achievement, which is similar to the previous findings [25-27]. The reasons may be related to the junior stage of work, lack of medical experience, deficiency of professional skills, difficulties and setbacks in work and distrust of patients. .

The cognitive situations of DPR tensity in doctors and patients were also evaluated, respectively. The doctors generally had a negative attitude towards DPR tensity, and thought that DPR was poor. On the contrary, patients' attitude toward DPR was obviously optimistic. Patients generally believed that DPR was good, and there was a deviation from doctors' poor cognition, which was consistent with previous study [28]. The difference in the cognitions of DPR tensity between doctors and patients, which creates obstacles for smooth communication and mutual understanding, may lead to tense DPR and conflict between doctors and patients [29].

It might have an effect of doctors' poor cognition of DPR tensity on their psychological 
condition, and bring antipathy towards patients, hospitals, departments and daily works. This could aggravate the sense of occupational burnout for doctors. Conversely, the high ratio and degree of occupational burnout may seriously endanger the quality of life, work enthusiasm and physical and mental health of doctors [30], which would lead to inefficiency in diagnosis and treatment, decline in service quality [7, 31-33], increase in risk of mistake and difficulties in communication with patients for doctors. These may strain DPR and proliferate the medical conflicts [34].

However, it is not clear whether is there the correlation between the degree of occupational burnout and cognition of DPR tensity in doctors? Few related studies were published. Some studies suggested that the rise in the sense of occupational burnout in doctors would cause tense DPR based on lack of quantitative evaluation [25,36]. Our study quantified the cognitive situation of DPR tensity in doctors by DDPRQ-8, and took the correlation analysis with the degree of occupational burnout. It was found that the degree of occupational burnout in doctors was significantly correlated with the cognition of DPR tensity. In three dimensions of emotional exhaustion, depersonalization and personal accomplishment, more than $60 \%$ of doctors with less burnout had a good cognition of DPR. With the increase of burnout degree, doctors' cognition of DPR tensity tended to deteriorate.

This suggests that the level of doctors' occupational burnout and their cognition of DPR tensity interact. Further study will be done to prove that whether improving the status quo 
of one of them might promote the improvement of the other's status.

Accordingly, the following measures are recommended. First, improve doctors' awareness of occupational burnout, popularize the self-assessment, and know their degrees of occupational burnout in time. Second, the psychological counseling and means of relief should be provided for doctors with occupational burnout as soon as possible, and the hospital should give the humane care and make the measures for pressure reduction to control the production and aggravation of occupational burnout in doctors. Third, doctors should know the cognitive difference between doctors and patients on DPR tensity, and patients' cognition is usually more optimistic than that of doctors, so as to provide preconditions and guarantee for the cognitive convergence on DPR tensity in order to reconstructing harmonious DPR. The measures above can reduce the degree of occupational burnout in doctors, which might change the doctors' poor cognition of DPR tensity into good cognition. This could reduce the iatrogenic risk of tense DPR, and promote the improvement of DPR.

In conclusion, doctors play a vital role in maintaining a normal DPR. The degree of doctors' occupational burnout is at a high level and correlated with the poor cognition of DPR tensity in China. Hospitals and society should care for the status quo of doctors' occupational burnout and take measures to improve it. It is possible to improve DPR by reducing the degree of doctors' occupational burnout. This will provide a new way for the 
formation and maintenance of good DPR.

\section{Acknowledgements}

This study was supported by the Medical Science and Technology Project of Henan

Province (Henan Health Commission, 201702212) and Key research projects of innovative projects for graduate students of Zhengzhou University (Zhengzhou University, DYCX051).

\section{Conflict of interest}

The authors declare no conflict of interest.

\section{References}

1. Chinese Medical Doctor Association. White paper on the practice status of Chinese doctors. 2019. http://www.cmt.com.cn/detail/1331701.html.

2. Makara-Studzińska M, Wontorczyk A, Izydorczyk B. Stress and occupational burnout in a population of Polish doctor - Organizational-professional and non-professionalsocial predictors. Ann Agric Environ Med 2019. 
3. West CP, Dyrbye LN, Erwin PJ, Shanafelt TD. Interventions to prevent and reduce physician burnout: a systematic review and meta-analysis. Lancet 2016; 388: 2272-81.

4. Dhingra M, Tewari R, Li M. Resilience training in medical school: the solution to doctor burnout? Med Teach 2016; 38: 319-20.

5. Zhou X, Pu j, Zhong X, Zhu D, Yin D, Yang L, Zhang Y, Fu Y, Wang H, Xie P; China Neurologist Association. Burnout, psychological morbidity, job stress, and job satisfaction in Chinese neurologists. Neurology 2017; 88: 1727-35.

6. Sablik Z, Samborska-Sablik A, Drozdz J. Universality of physicians' burnout syndrome as a result of experiencing difficulty in relationship with patients. Arch Med Sci 2013; 9: 398-403.

7. Zheng X, Guo WQ, Chen Y, Su J. Investigation on occupational burnout among doctors in stomatology department in Hainan Province. J Kunming Med Univ 2016; 37: 131-4.

8. Wu H, Liu L, Wang Y, Gao F, Zhao X, Wang L. Factors associated with burnout among Chinese hospital doctors: a cross-sectional study. BMC Public Health 2013; 13: 786-8.

9. Hahn SR. Physical symptoms and physician-experienced difficulty in the physicianpatient relationship. Ann Intern Med 2001; 134: 897-904. 
10. Wu H, Zhao X, Fritzsche K, Leonhart R, Schaefert R, Sun X, Larisch A. Quality of doctor-patient relationship in patients with high somatic symptom severity in China. Complement Ther Med 2015; 23: 23-31.

11. Van der Feltz-Cornelis CM, Van Oppen P, Van Marwijk HW, De Beurs E, Van Dyck R. A patient-doctor relationship questionnaire (PDRQ-9) in primary care: development and psychometric evaluation.

Gen Hosp Psychiatry 2004; 26: 115-20.

12. Mingote Adán J, Moreno Jiménez B, Rodríguez Carvajal R, Gálvez Herrer M, Ruiz López P. Psychometric validation of the Spanish version of the Patient-Doctor Relationship Questionnaire (PDRQ). Actas Esp Psiquiatr 2009; 37: 94-100.

13. Martín-Fernández J, del Cura-González MI, Gómez-Gascón T, Fernández-López E, Pajares-Carabajal G, Moreno-Jiménez B. Patient satisfaction with the patient-doctor relationship measured using the questionnaire (PDRQ-9). Aten Primaria 2010; 42: 196-203.

14. Porcerelli JH1, Murdoch W, Morris P, Fowler S. The PatientDoctor Relationship Questionnaire (PDRQ-9) in Primary Care: A Validity Study. J Clin Psychol Med Settings 2014; 21: 291-6.

15. Yang H, Wang HQ. Reliability and validity of Chinese version of doctor-patient relationship scale PDRQ-15. Chinese Med Ethics 2011; 24: 350-3. 
16. Yang H. Development and Evaluation of Chinese Version PDRQ/DDPRQ Scale: Quantitative Study of Doctor-patient Relationship. Datong: Shanxi Medical University; 2011.

17. Freudenberger HJ. Staff Burnout. J Soc Issues 1974; 30: 159-165.

18. Mazur A, Czarkowska M, Goś A, Humeniuk E. Existential attitudes as predictors of burnout in Polish nurses employed in rural primary healthcare settings. Ann Agric Environ Med 2018; 25: 552-558.

19. Wu H, Liu L, Wang Y, Gao F, Zhao X, Wang L. Factors associated with burnout among Chinese hospital doctors: a cross-sectional study. BMC Public Health 2013; 13: 7868.

20. Dyrbye LN, Shanafelt TD. Physician burnout: a potential threat to successful health care reform. JAMA 2011; 305: 2009-10.

21. Makara-Studzińska M, Załuski M, Tylec A, Panasiuk L. Do Polish doctors suffer from occupational burnout syndrome? An attempt to find an answer - Pilot study. Ann Agric Environ Med 2019; 26: 191-197.

22. Kupcewicz E, Jóźwik M. Association of burnout syndrome and global self-esteem among Polish nurses. Arch Med Sci 2020; 16: 135-45. 
23. Leszczyński P, Panczyk M, Podgórski M, Owczarek K, Gałązkowski R, Mikos M, Charuta A, Zacharuk T, Gotlib J. Determinants of occupational burnout among employees of the Emergency Medical Services in Poland. Ann Agric Environ Med 2019; 26: 114-119.

24. Mcmanus IC, Keeling A, Paice E. Stress, burnout and doctors' attitudes to work are determined by personality and learning style: A twelve year longitudinal study of UK medical graduates. BMC Medicine 2004; 2: 29.

25. Ogundipe OA, Olagunju AT, Lasebikan VO, Coker AO. Burnout among doctors in residency training in a tertiary hospital. Asian J Psychiatr 2014; 10: 27-32.

26. Brewer EW, Sharpard L. Employee burnout: a meta-analysis of the relationship between age or years of experience. Human Resource Development Review 2004; 3 : $102-23$.

27. Woodside JR, Miller MN, Floyd MR, McGowen KR, Pfortmiller DT. Observations on burnout in family medicine and psychiatry resident. Acad Psychiatry 2008; 32: 13-9.

28. Shen WW, Bao Y. Cognitive Differences between Doctors and Patients on Doctorpatient Relations. Chinese General Practice 2015; 18: 2329-32.

29. Robinson G. Effective doctor patient communication: building bridges and bridging barriers. Can J Neurol Sci 2002; 29: 30-2. 
30. Ekstedt M, Söderström M, Åkerstedt T, Nilsson J, Søndergaard H-P, Aleksander P. Disturbed sleep and fatigue in occupational burnout. Scand J Work Environ Health 2006; 32: 121-31.

31. Montgomery A, Panagopoulou E, Kehoe I, Valkanos E. Connecting organisational culture and quality of care in the hospital: is job burnout the missing link? J Health Organ Manag 2011; 25: 108-23.

32. Shanafelt TD, Gradishar WJ, Kosty M, Satele D, Chew H, Horn L, Clark B, Hanley AE, Chu Q, Pippen J, Sloan J, Raymond M. Burnout and Career Satisfaction Among US Oncologists. J Clin Oncol 2014; 32: 678-86.

33. Williams ES, Manwell LB, Konrad TR, Linzer M. The relationship of organizational culture, stress, satisfaction, and burnout with physician-reported error and suboptimal patient care: results from the MEMO study. Health Care Manage Rev 2007; 32: 20312.

34. Wen J, Cheng Y, Hu X, Yuan P, Hao T, Shi Y. Workload, burnout, and medical mistakes among physicians in China: A cross-sectional study. Biosci Trends 2016; 10: 27-33.

35. Cohen D, Rhydderch M, Reading P, Williams S. Doctors' health: obstacles and enablers to returning to work. Occup Med (Lond) 2015; 65: 459-65. 
36. Merrett A, Jones D, Sein K, Green T, Macleod U. Attitudes of newly qualified doctors towards a career in general practice: a qualitative focus group study. Br J Gen Pract 2017; 67: e253-9. 


\section{Tables}

Table I. The Difficult Doctor-Patient Relationship Questionnaire-8 (DDPRQ-8) for doctors

\begin{tabular}{|c|c|c|c|c|c|c|}
\hline Contents & \multicolumn{6}{|c|}{ Scores } \\
\hline 1. Do you want to visit your patients next time after you see them today? & 1 & 2 & 3 & 4 & 5 & 6 \\
\hline 2. Do you find that some of your patients are frustrated? & 1 & 2 & 3 & 4 & 5 & 6 \\
\hline 3. Do your patients want to control your decision about disease diagnosis and treatment? & 1 & 2 & 3 & 4 & 5 & 6 \\
\hline 4. Are you annoyed or frustrated by your patients' vague complaints about their diseases? & 1 & 2 & 3 & 4 & 5 & 6 \\
\hline 5. Do your patients have a tendency to abandon themselves? & 1 & 2 & 3 & 4 & 5 & 6 \\
\hline 6. Do you find yourself secretly (privately) wishing your patients would not come back? & 1 & 2 & 3 & 4 & 5 & 6 \\
\hline 7. Do you think it's time consuming to take care of your patients? & & 2 & 3 & 4 & 5 & 6 \\
\hline 8. Are you having trouble communicating with your patients? & 1 & 2 & 3 & 4 & 5 & 6 \\
\hline
\end{tabular}

1-never; 2-no; 3-a little; 4-yes nearly; 5-yes; 6 yes strongly. 
Table II. The Patient-Doctor Relationship Questionnaire-13 (PDRQ-13) for patients

\begin{tabular}{|c|c|c|c|c|c|}
\hline Contents & \multicolumn{5}{|c|}{ Scores } \\
\hline 1. My doctor knows me. & 1 & 2 & 3 & 4 & 5 \\
\hline 2. I trust my doctor. & 1 & 2 & 3 & 4 & 5 \\
\hline 3. My doctor helped me very seriously. & 1 & 2 & 3 & 4 & 5 \\
\hline 4. I can talk to my doctor. & 1 & 2 & 3 & 4 & 5 \\
\hline 5. I am satisfied with my doctor's treatment. & 1 & 2 & 3 & 4 & 5 \\
\hline 6. I think my doctor can find out in time that I have difficulty in dealing with the disease. & 1 & 2 & 3 & 4 & 5 \\
\hline 7. My doctor will help me. & 1 & 2 & 3 & 4 & 5 \\
\hline 8. My doctor will give me plenty of time. & 1 & 2 & 3 & 4 & 5 \\
\hline 9. I benefit from my doctor's treatment. & 1 & 2 & 3 & 4 & 5 \\
\hline 10. My doctor and I agree on the problem with my medical symptoms. & 1 & 2 & 3 & 4 & 5 \\
\hline
\end{tabular}


11. I feel my doctor very approachable.

12. I thank my doctor because I feel better.

13. I thank my doctor who has given me a new understanding.
1
2

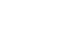

$\begin{array}{llll}2 & 3 & 4 & 5\end{array}$

2

3

45

1-quite agree; 2-agree; 3-unclear; 4-disagree; 5-quite disagree. 
Table III. The scores of doctors' occupational burnout degree under the baseline information

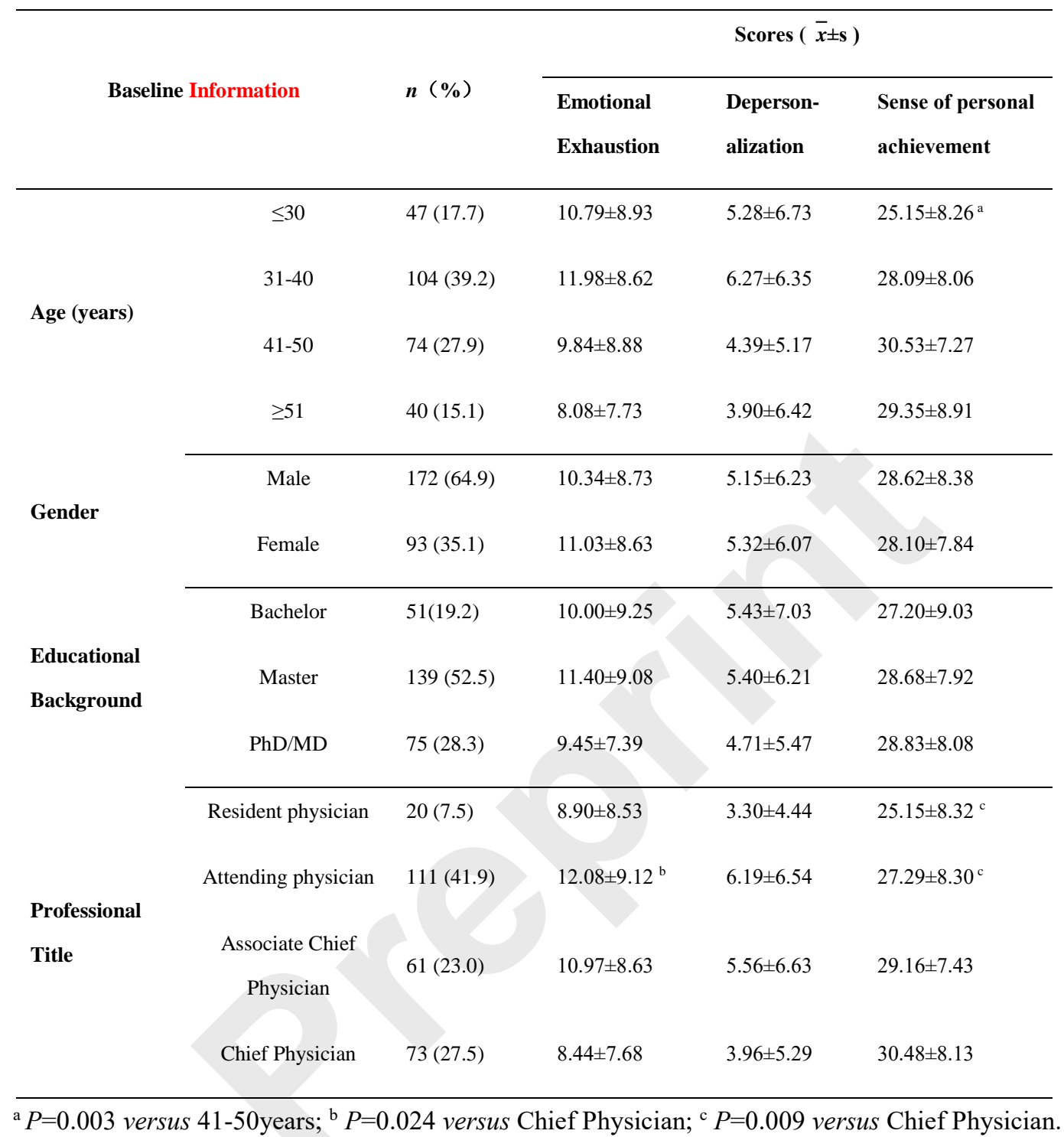


Table IV. The degree proportions of occupational burnout among doctors $(n(\%))$

\begin{tabular}{lccc}
\hline \multirow{2}{*}{ Dimension } & \multicolumn{3}{c}{ Degree } \\
\cline { 2 - 4 } & Mild & Moderate & Severe \\
\hline Emotional Exhaustion & $133(50.2)$ & $40(15.1)$ & $92(34.7)$ \\
Depersonalization & $124(46.8)$ & $84(31.7)$ & $57(21.5)$ \\
Sense of personal achievement & $136(51.3)$ & $95(35.8)$ & $34(12.8)$ \\
\hline
\end{tabular}


Table V. Cognitive Scores of DPR Tensity in Doctors and Patients in Clinical Departments

\begin{tabular}{lcc}
\hline \multirow{2}{*}{ Department } & \multicolumn{2}{c}{ Cognitive score $\left(\overline{\boldsymbol{x}}_{ \pm \mathbf{s}}\right)$} \\
\cline { 2 - 3 } & & \multicolumn{2}{c}{ DDPRQ-8 (doctor) } & PDRQ-13 (patient) \\
\hline Neurology & $24.93 \pm 9.15$ & $19.09 \pm 1.54$ \\
Gastroenterology and hepatology & $25.29 \pm 9.24$ & $18.00 \pm 3.76$
\end{tabular}




\begin{tabular}{|c|c|c|}
\hline Respiratory & $30.67 \pm 4.74$ & $18.58 \pm 4.95$ \\
\hline Cardiovascular & $22.82 \pm 4.42$ & $16.79 \pm 3.64$ \\
\hline Nephropathy and rheumatism & $21.33 \pm 6.30$ & $17.08 \pm 4.15$ \\
\hline Hematology & $24.08 \pm 6.02$ & $18.78 \pm 5.74$ \\
\hline Endocrine & $20.60 \pm 3.76$ & $17.82 \pm 3.97$ \\
\hline Oncology & $21.21 \pm 4.79$ & $19.45 \pm 6.42$ \\
\hline Gastrointestinal surgery & $25.75 \pm 5.33$ & $14.31 \pm 1.67$ \\
\hline Thyroid and mammary surgery & $24.07 \pm 6.02$ & $14.33 \pm 1.97$ \\
\hline Urology surgery & $20.62 \pm 3.99$ & $15.33 \pm 2.74$ \\
\hline Hepatobiliary surgery & $21.64 \pm 6.02$ & $15.67 \pm 2.23$ \\
\hline Orthopeadic surgery & $18.70 \pm 6.02$ & $15.37 \pm 1.93$ \\
\hline Thoracic surgery & $23.00 \pm 7.80$ & $13.54 \pm 0.59$ \\
\hline Neurosurgery & $25.08 \pm 8.08$ & $13.95 \pm 1.47$ \\
\hline Cardiac surgery & $22.33 \pm 4.72$ & $14.30 \pm 1.59$ \\
\hline Obstetrics and gynecology & $20.50 \pm 6.06$ & $15.13 \pm 2.59$ \\
\hline Pediatrics & $23.36 \pm 6.36$ & $14.85 \pm 2.19$ \\
\hline Otorhinolaryngology & $20.90 \pm 6.97$ & $17.90 \pm 3.42$ \\
\hline Ophthalmology & $21.27 \pm 7.80$ & $15.65 \pm 2.29$ \\
\hline Emergency & $26.07 \pm 6.17$ & $20.05 \pm 4.26$ \\
\hline Intensive care unit & $24.30 \pm 4.95$ & $22.67 \pm 4.07$ \\
\hline
\end{tabular}

DPR, doctor-patient relationship. 
Table VI. Component Ratios of Cognitions of DPR Tensity in Doctors and Patients

\begin{tabular}{|c|c|c|c|c|c|}
\hline \multirow{3}{*}{ Object } & \multirow{3}{*}{$n$} & \multicolumn{4}{|c|}{ Cognitive Ratio } \\
\hline & & \multicolumn{2}{|c|}{ Good cognition } & \multicolumn{2}{|c|}{ Poor cognition } \\
\hline & & $n$ & Percent (\%) & $n$ & Percent (\%) \\
\hline Doctor & 265 & 148 & 55.85 & 117 & 44.15 \\
\hline Patient & 782 & 759 & 97.06 & 23 & 2.94 \\
\hline
\end{tabular}

$\chi^{2}=290.178, P<0.0001$. DPR, doctor-patient relationship. 


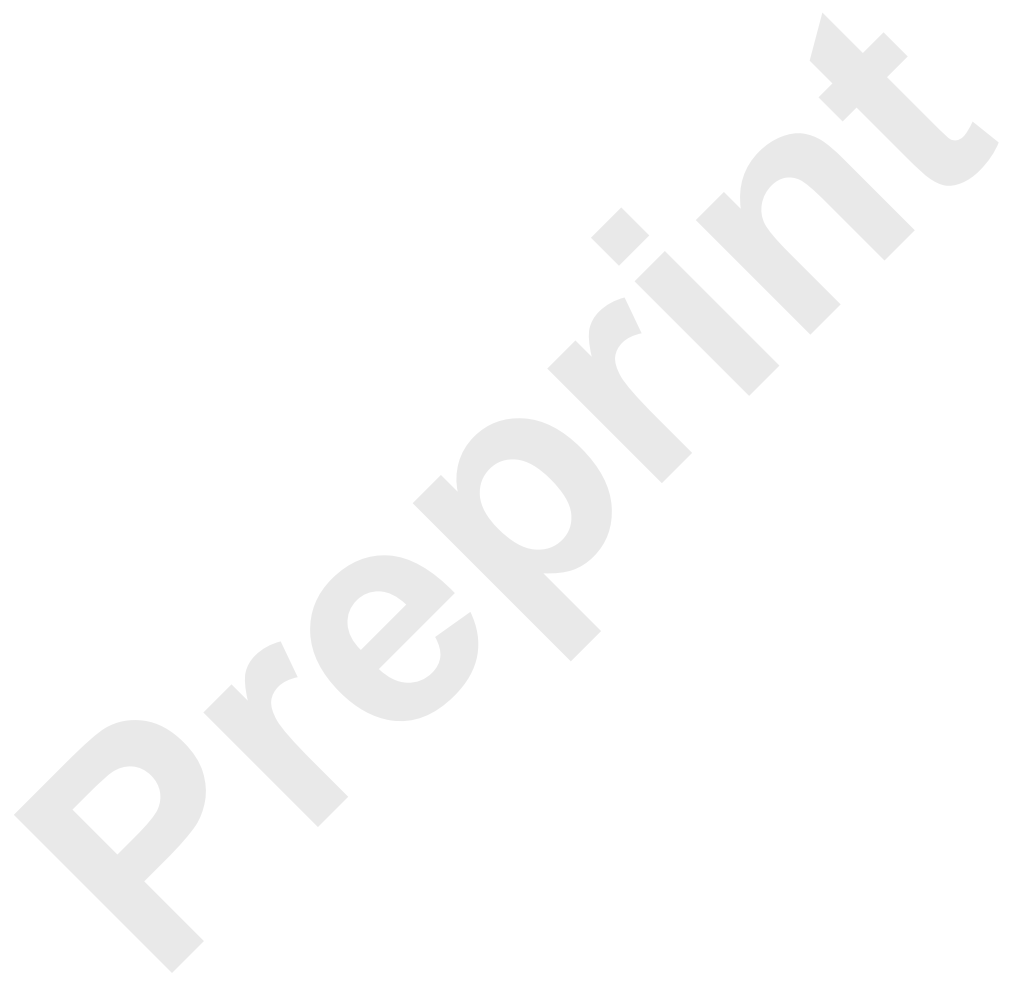


Table VII . The Degree Proportions of Cognitions of DPR Tensity in Doctors with Occupational Burnout (n(\%))

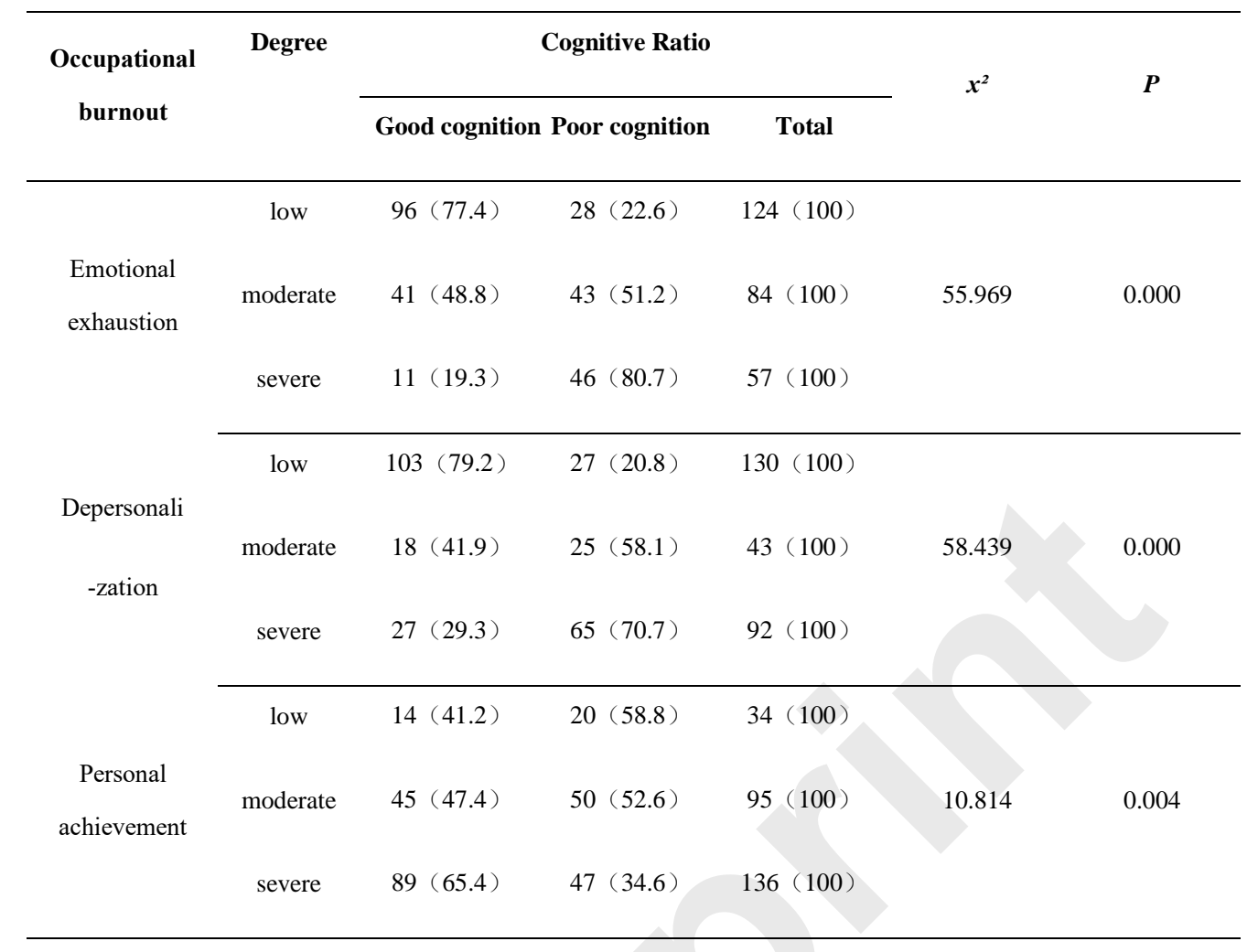

DPR, doctor-patient relationship. 


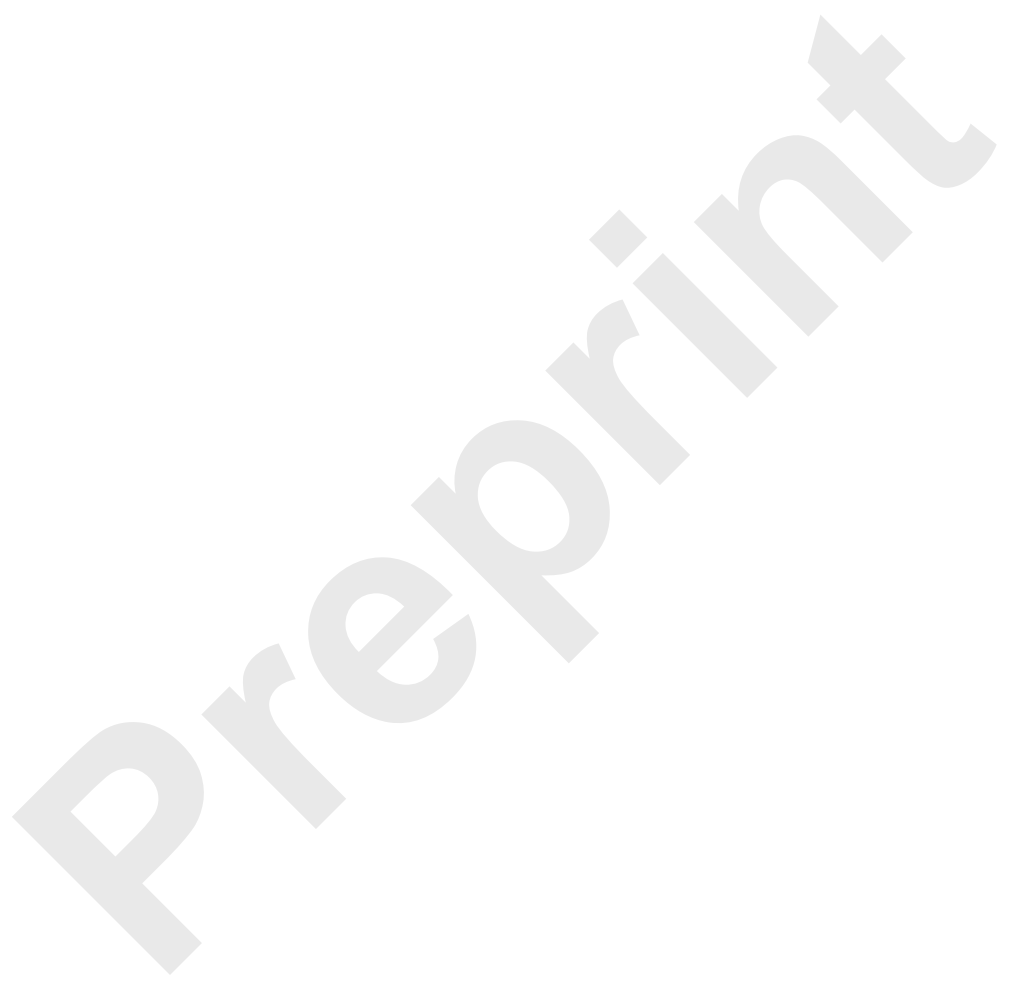



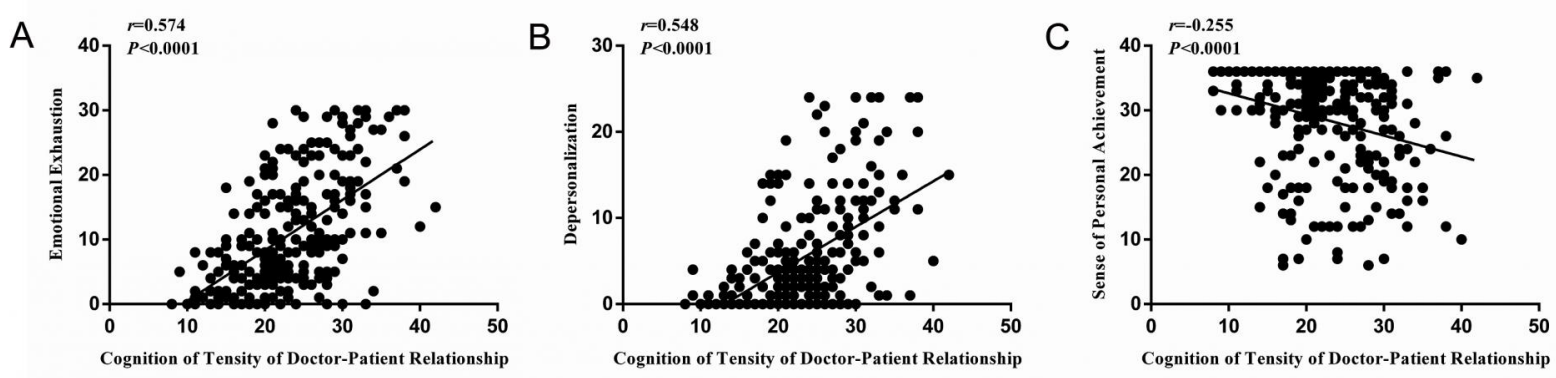

Figure 1 The correlation between three dimensions of occupational burnout and cognition of tensity of doctor-patient relationship (DPR) in doctors. (A) The emotional exhaustion was positively correlated with the poor cognition of DPR tensity $(r=0.574, P<0.0001)$. (B) The depersonalization was positively correlated with the poor cognition of DPR tensity $(r=0.548$, $P<0.0001)$. (C) The sense of personal achievement was negatively correlated with the poor cognition of DPR tensity $(r=-0.255, P<0.0001)$. 